
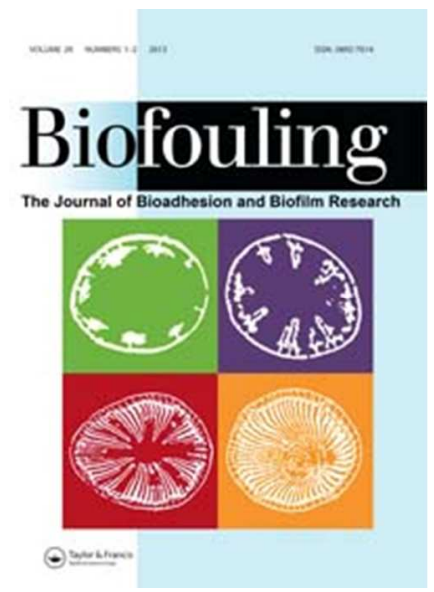

Adsorption of a PEO-PPO-PEO triblock copolymer on metal oxide surfaces with a view to reduce protein adsorption and further biofouling

\begin{tabular}{|r|l|}
\hline Journal: & Biofouling \\
\hline Manuscript ID: & GBIF-2013-0091.R2 \\
\hline Manuscript Type: & Original Paper \\
\hline Keywords: & $\begin{array}{l}\text { quartz crystal microbalance, Pluronic, biofouling, surface modification, } \\
\text { metal oxide, protein adsorption }\end{array}$ \\
\hline \multicolumn{2}{|l}{} \\
\hline
\end{tabular}

SCHOLARONE $^{\text {th }}$
Manuscripts 


\section{Adsorption of a PEO-PPO-PEO triblock copolymer on metal oxide surfaces} with a view to reduce protein adsorption and further biofouling

Y. Yang ${ }^{\mathrm{a}}$, C. Poleunis ${ }^{\mathrm{a}}$, L. Románszki ${ }^{\mathrm{b}}, \mathrm{J}_{\text {. Telegdi }}^{\mathrm{b}, \mathrm{c}}$, C.C. Dupont-Gillain ${ }^{\mathrm{a}}$

${ }^{a}$ Surfaces group (SURF), Bio- and Soft Matter (BSMA), Institute of Condensed Matter and Nanosciences (IMCN), Université catholique de Louvain, Croix du Sud 1 bte L7.04.01, 1348

Louvain-la-Neuve, Belgium; ${ }^{b}$ Department of interfaces and surface modification, Institute of Materials and Environmental Chemistry, Research Centre for Natural Sciences, Hungarian Academy of Sciences, Pusztaszeri út 59/67, 1025 Budapest, Hungary; ${ }^{c}$ Rejtő Sándor Faculty of Light Industry and Environmental Engineer, Institute of Media Technology and Light Industry, Óbuda University, Doberdó út 6, Budapest, Hungary

Yi Yang: yi.yang@uclouvain.be Tel: 32-10-47 3595

Claude Poleunis: claude.poleunis@uclouvain.be Tel: 32-10-473582

Loránd Románszki: romanszki.lorand@ttk.mta.hu Tel: 36-1-438 1100/176

Judit Telegdi: telegdi.judit@,ttk.mta.hu Tel: 36-30-4754199

*Corresponding author

Christine C. Dupont-Gillain: christine.dupont@uclouvain.be

Tel: 32-10-47 35 84; Fax: 32-10-47 2005

Text: 6197 words

References: 1297 words

Figures: 392 words

Table: 233 words

TOTAL: 6822 words 


\title{
Adsorption of PEO-PPO-PEO triblock copolymer on metal oxide surfaces with a view to reduce protein adsorption and further biofouling
}

\author{
Biomolecule adsorption is the first stage of biofouling. The aim of this work is to reduce \\ protein adsorption on stainless steel and titanium surfaces by modifying them with a \\ poly(ethylene oxide) (PEO)-poly(propylene oxide) (PPO)-PEO triblock copolymer. \\ Anchoring of the central PPO block of the copolymer is known to be favored by \\ hydrophobic interaction with the substrate. Therefore, the metal oxide surfaces were \\ first modified by self-assembly of octadecylphosphonic acid (OPA). PEO-PPO-PEO \\ preadsorbed on the hydrophobized titanium or stainless steel was shown to prevent \\ bovine serum albumin (BSA), fibrinogen and cytochrome $\mathrm{C}$ adsorption, as was \\ monitored by quartz crystal microbalance (QCM). Moreover, X-ray photoelectron \\ spectroscopy (XPS) and time-of-flight secondary ion mass spectrometry (ToF-SIMS) \\ were used to characterize stainless steel and titanium surfaces after competitive \\ adsorption of PEO-PPO-PEO and BSA. The results show that BSA adsorption is well \\ prevented on hydrophobized surfaces, in contrast to native metal oxide surfaces.
}

Keywords: quartz crystal microbalance (QCM), PEO-PPO-PEO, biofouling, surface modification, metal oxide, protein adsorption 


\section{Introduction}

Biofouling or bioadhesion (Kingshott \& Griesser 1999) refer to uncontrolled and irreversible accumulation of biological material on synthetic surfaces, leading to the formation of a biofilm. The accumulation of biofilm on metallic materials can bring adverse effects, as illustrated in Table 1.

The initial step of biofouling of materials consists in the spontaneous adsorption of biomolecules present in the aqueous environment (Boonaert et al. 2003; Schneider \& Leis 2003). It is indeed recognized that bacteria adhere onto material surfaces through a conditioning film composed of proteins and polysaccharides (Compère et al. 2001). The formation of a protein layer on the material surface is actually thought to be a requisite for microorganism adhesion which might be attributed to specific recognitions. Adsorbed proteins could moreover serve as concentrated nutrients to attract microorganisms. Adsorption of proteins on metal surfaces is therefore particularly important with respect to biofouling problems. Proteins are known to be the major constituent of fouling substances due to their high activity and affinity toward metal surfaces. Therefore, an efficient surface modification strategy to prevent protein adsorption on metallic surfaces is highly desired.

Immobilization of poly(ethylene oxide) (PEO) on surfaces (Leckband et al. 1999) is currently the most common method to reduce protein adsorption on metallic materials, through chemical adsorption using a "grafting to" or a "grafting from" approach (Zhao \& Brittain 2000), or through physical adsorption of block or graft copolymers (Michel et al. 2005). The protein resistance properties of hydrophilic PEO-based surfaces are mainly attributed to steric repulsion between proteins and the highly hydrated and flexible PEO chains (Amiji \& Park 1992; Rosenhahn et al. 2010). Poly(L-lysine)-g-PEG (PLL-g-PEG, where PEG stands for poly(ethylene glycol), a synonym of PEO) is well-known to anchor to negatively charged metal oxide surfaces through the positively charged PLL backbone 
(Kenausis et al. 2000), and is efficient to reduce protein adsorption. However, the amount of adsorbed PLL-g-PEG on metal oxide surfaces is $\mathrm{pH}$ - and ionic strength-dependent.

PEO-PPO-PEO (where PPO stands for poly(propylene oxide)) triblock copolymers, commercially available under the name of Pluronic ${ }^{\circledR}$, can also be used to form PEO-based polymer coatings through adsorption on hydrophobic surfaces (Freij-Larsson et al. 1996), thereby reducing protein adsorption (Green et al. 1998). Pluronic ${ }^{\circledR}$ is commonly used as a non-ionic polymeric surfactant in chemical and pharmaceutical industries (Amiji \& Park 1992; Green et al. 1997). The more apolar PPO block of the triblock copolymer is expected to interact with hydrophobic surfaces, leaving free PEO chains extending into the bulk aqueous medium (Dewez et al. 1996). There are a wide range of PEO-PPO-PEO triblock copolymers with varying PEO and PPO chain lengths. The conformation and density of adsorbed PEOPPO-PEO on hydrophobic surfaces vary depending on chain length of PEO and PPO blocks. It has been reported (Dewez et al. 1996) that collagen adsorption and epithelial cell adhesion were prevented on hydrophobic substrates in the presence of Pluronic ${ }^{\circledR}$ F68. It is expected that, more generally, PEO-PPO-PEO can reduce biomolecule adsorption (Caldwell 1997), bacterial adhesion (Nejadnik et al. 2008) and thus biofilm formation. However, until now, to the best of our knowledge, a PEO-PPO-PEO triblock copolymer has not been immobilized on metal oxide surfaces to reduce protein adsorption, due to the hydrophilic nature of such surfaces. The results of Nejadnik show that the adsorbed layer of Pluronic F127 is less than $2 \mathrm{~nm}$ thick on titanium oxide, suggesting a pancake rather than brush conformation, but these authors did not further investigate the protein resistance of the layer (Nejadnik et al. 2009).

Several methods have been reported to hydrophobize the surface of metal oxides by modifying surface chemistry and possibly also surface topography, eg by means of selfassembled monolayers (SAM) or by introducing nano- or microstructures (Chen et al. 2008; Li et al. 2012). Self-assembly of small molecules on metal surfaces is widely used to modify 
their properties. Alkylthiols and more generally organosulfur compounds are commonly assembled on gold or silver (Ulman 1996; Love et al. 2005). Such strategy can however not be used on metal oxide surfaces. The self-assembly of alkylsilanes is another possible approach, but the control of assembly and the stability of the obtained layers raise many issues (Dekeyser et al. 2008; Dekeyser et al. 2012). Recently, self-assembly of alkane phosphonic acid has been applied on a wide range of metal oxide surfaces, including stainless steel (Van Alsten 1999), aluminium oxide (Nie 2010), copper oxide (Hoque et al. 2009), copper-nickel alloy (Kruszewski et al. 2012) and titanium oxide (Gawalt et al. 2001). It was reported that alkane phosphonic acid molecules bind covalently to the oxide surface (Helmy \& Fadeev 2002). The bonding mode (eg monodentate, bidentate or tridentate) however highly depends on the substrate (Fonder et al. 2011). It was showed that the water contact angle of copper oxide modified with a self-assembled monolayer of octadecylphosphonic acid is higher than $140^{\circ}$ (Hoque et al. 2009).

The aim of this study is to design a protein-resistant layer on metal oxide surfaces (titanium and stainless steel) by a two-step approach (Figure 1). First, self-assembly of octadecylphosphonic acid (OPA) was performed on titanium or stainless steel to obtain a hydrophobic surface, which is expected to favor PEO-PPO-PEO adsorption. The ability of PEO-PPO-PEO to prevent protein adsorption was then tested in two ways. On the one hand, PEO-PPO-PEO was preadsorbed on OPA-conditioned titanium or stainless steel, and the subsequent adsorption of three different model proteins (bovine serum albumin, fibrinogen, cytochrome C) was monitored by quartz crystal microbalance (QCM), a well-suited tool to monitor the successive deposition of the copolymer and the proteins. On the other hand, the competitive adsorption of PEO-PPO-PEO and BSA was examined using X-ray photoelectron spectroscopy (XPS) and time-of-flight secondary ion mass spectrometry (ToF-SIMS). These surface-sensitive techniques allow the respective presence of the copolymer and the protein in 
the adsorbed layer to be established. All experiments were performed in artificial seawater to mimic the conditions encountered in the case of marine biofouling.

\section{Experimental}

\section{Materials}

Albumin (BSA, from bovine serum), fibrinogen ( $\mathrm{Fb}$, fraction I, type I, from human

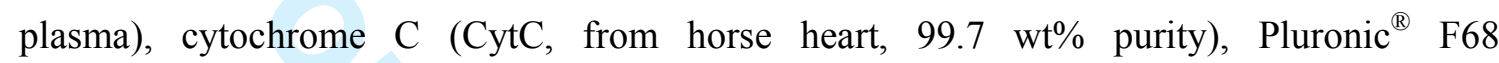
(polyethylene oxide (PEO)-polypropylene oxide (PPO)-polyethylene oxide block copolymer with a degree of polymerization of 76 for the PEO blocks and 30 for the central PPO block $\left(\mathrm{PEO}_{76} \mathrm{PPO}_{30} \mathrm{PEO}_{76}\right)$ and a molar mass of $\left.8350 \mathrm{Da}\right)$, in short Plu in the following text, and octadecylphosphonic acid (97 wt\%, OPA) were purchased from Sigma-Aldrich, and used without further purification.

Artificial seawater (ASW) (Berglin \& Elwing 2008) (see composition in Table 2) was sterilized after preparation, and then stored at $4{ }^{\circ} \mathrm{C}$. Filtered $(0.2 \mu \mathrm{m})$ ASW was used to prepare protein and Plu solutions. BSA (65 kDa) (Carter \& Ho 1994), Fb (340 kDa) (Haynes \& Norde 1994), CytC (11.7 kDa) (Nakanishi et al. 2001) and Plu were dissolved in ASW at a concentration of $0.2,0.1,0.5$ and $2 \mathrm{mg} \mathrm{mL}^{-1}$, respectively. It was checked that at these concentrations, these proteins reach their adsorption plateau over a short period of time. Regarding Plu, in a preliminary experiment, adsorption was performed on hydrophobic polystyrene with sequential increase of concentration, and monitored by QCM. It was concluded that the adsorbed Plu amount reaches a plateau after a short period of time using 2 $\mathrm{mg} \mathrm{mL}^{-1}$. The plateau value did not increase anymore upon further increase of the concentration (results now shown).

Stainless steel $304(\mathrm{SS})$ plates were $1 \times 1 \mathrm{~cm}^{2}$ squares, in short SS, with $1 \mathrm{~mm}$ thickness and mirror-like surfaces received from Arcelor Mittal (Belgium). Titanium samples 
(Ti, diameter of $1.2 \mathrm{~cm}$ ) were cut from cooling condenser tubes purchased from Ricerca sul Sistema Energetico (RSE) S.p.A (Italy), squeezed into relatively flat surfaces, and handpolished using emery paper with grain size 600, then 1200. SS and Ti samples were cleaned three times with acetone in an ultrasonic bath for $15 \mathrm{~min}$, and then submitted to UV-ozone cleaning for $15 \mathrm{~min}$ just before any further experiment.

\section{Self-assembled monolayer preparation}

Octadecylphosphonic acid (OPA) was dissolved in tetrahydrofuran (THF) at a concentration of $0.01 \mathrm{M}$. The cleaned metallic samples were immersed in OPA solution for 24 h. After removal from solution, the samples were rinsed 3 times with fresh THF in order to remove physisorbed molecules from the substrate surface, and dried in room conditions. The OPA-modified samples are referred to as Ti/OPA or SS/OPA.

\section{Water contact angle (WCA) measurements}

The wettability of metal surfaces before and after coating with OPA was investigated by measuring the contact angle using the sessile water drop method. A water drop of $1 \mu$ was used for measurement at room temperature, and the contact angle was recorded $5 \mathrm{~s}$ after the water drop was deposited on the sample. For each type of sample, the reported value is the average of measurements made on triplicate samples (4 drops each).

\section{Quartz crystal microbalance with dissipation monitoring (QCM-D)}

The AT-cut quartz crystals, coated with either titanium (QSX310) or stainless steel 2343 (QSX304, similar to US standard 316), with a fundamental resonant frequency of 5 $\mathrm{MHz}$ and a diameter of $14 \mathrm{~mm}$, were purchased from LOT-ORIEL Europe. The experiments were performed using a Q-Sense E4 instrument (Q-Sense, Gothenburg, Sweden). The crystals were cleaned according to the protocol provided by Q-Sense. All experiments were carried 
out at $20^{\circ} \mathrm{C}$ and the flow, driven by a peristaltic pump, was set at $50 \mu 1 \mathrm{~min}^{-1}$. The resonance frequency and dissipation were monitored simultaneously, and the results were recorded for different overtones (overtone number $\mathrm{n}=1,3,5,7,9,11,13$ ).

The principle and applications of QCM have been reviewed elsewhere (Marx 2003). In summary, the recorded shifts of frequency $(\Delta \mathrm{f})$ are proportional to the mass loaded on the surface of the crystal while the changes of dissipation $(\Delta \mathrm{D})$ are related to the viscoelastic properties of the adsorbed layer. If the adsorbed layer is assumed to be rigid and evenly distributed, the changes of adsorbed mass $(\Delta \mathrm{m})$ can be calculated from $\Delta \mathrm{f}$, based on Sauerbrey equation (1) as follows:

$$
\Delta m=-\frac{c \times \Delta f}{n}
$$

Where $\mathrm{c}=17.7 \mathrm{ng} \mathrm{Hz}^{-1} \mathrm{~cm}^{-2}$ for a $5 \mathrm{MHz}$ quartz crystal and $\mathrm{n}$ is the overtone number. Note that all observed $\Delta \mathrm{D} / \Delta \mathrm{f}$ ratios recorded here were lower than $0.4 \times 10^{-6}$ (data not shown). Therefore, $\Delta \mathrm{f}$ may be considered proportional to the mass of the adsorbed layer (Reviakine et al. 2011) as described by Sauerbrey equation. Adsorbed Plu or protein mass was determined using all overtones except $\mathrm{n}=1$.

Artificial seawater was used as the background solution in all the experiments and was flowed into QCM cells for at least $1 \mathrm{~h}$ before performing adsorption steps, to ensure a flat baseline. To avoid bubbles, all solutions were degassed before use.

\section{X-ray photoelectron spectroscopy (XPS)}

XPS measurements were carried out with a Kratos Axis Ultra spectrometer (Kratos Analytical, UK), using monochromated $\mathrm{Al} \mathrm{K \alpha}$ radiation (powered at $10 \mathrm{~mA}$ and $15 \mathrm{kV}$ ) and an eight-channeltrons detector. The analyzed area was $700 \times 300 \mu \mathrm{m}^{2}$. The vacuum in the analysis chamber was about $10^{-6} \mathrm{~Pa}$. The direction of photoelectron collection was 
perpendicular to the sample surface. Charging stabilization was achieved by using the Kratos Axis device. Survey spectra were recorded with $160 \mathrm{eV}$ pass energy and $40 \mathrm{eV}$ pass energy was used for narrow scans. In the latter conditions, the full width at half maximum (FWHM) of the $\mathrm{Ag} 3 \mathrm{~d}_{5 / 2}$ peak of a standard silver sample was about $0.9 \mathrm{eV}$. The $\underline{\mathrm{C}}-(\mathrm{C}, \mathrm{H})$ component of the $\mathrm{C} 1 \mathrm{~s}$ peak of carbon has been fixed to $284.8 \mathrm{eV}$ to set the binding energy scale. The following sequence of spectra was recorded: survey spectrum, C 1s, O 1s, N 1s, Si 2p, P 2p, $\mathrm{Cl} 2 \mathrm{p}, \mathrm{S} 2 \mathrm{p}, \mathrm{Ca} 2 \mathrm{p}, \mathrm{Na} 1 \mathrm{~s}, \mathrm{Mg} 2 \mathrm{p},(\mathrm{Cr} 2 \mathrm{p}, \mathrm{Mn} 2 \mathrm{p}, \mathrm{Fe} 2 \mathrm{p}, \mathrm{Zn} 2 \mathrm{p}, \mathrm{Sn} 3 \mathrm{~d}$ for SS, Ti 2p, Zn 2p, Fe $2 \mathrm{p}$ for $\mathrm{Ti}$ ) and $\mathrm{C} 1 \mathrm{~s}$ again to check for charge stability and absence of degradation as a function of time. Molar fractions were calculated after a linear background subtraction using peak areas normalized on the basis of acquisition parameters, experimental sensitivity factors and transmission factors provided by the manufacturer. Elemental mole fractions are provided, excluding hydrogen which is not detected by XPS. The C 1s spectra were decomposed with the CasaXPS program (Casa Software Ltd., U.K) using a Gaussian/Lorentzian (70/30) product function. The FWHM of the four carbon components was kept identical.

\section{Time-of-flight secondary ion mass spectrometry (ToF-SIMS)}

ToF-SIMS measurements were performed with an ION-TOF V (ION-TOF, GmbH, Münster, Germany) spectrometer, using a $\mathrm{Bi}_{3}{ }^{+}$primary ion source. The analyzed area was 500 $\times 500 \mu \mathrm{m}^{2}$ and the acquisition time for each spectrum was $1 \mathrm{~min}$. Three positive spectra were acquired on each sample with a pulsed $30 \mathrm{keV}, 0.67 \mathrm{pA}$ primary ion beam in the high current bunched mode. The total ion dose density was $1.1 \times 10^{11} \mathrm{Bi}_{3}{ }^{+} \mathrm{cm}^{-2}$, below the static SIMS limit. The mass resolution $(\mathrm{m} / \Delta \mathrm{m})$ of the positive secondary ion spectra was 9700 for $\mathrm{C}_{4} \mathrm{H}_{7}{ }^{+}$. ToF-SIMS imaging from negative spectra was obtained in 10 min using a $\mathrm{Bi}_{3}{ }^{++}$primary ion source, with a pulsed $60 \mathrm{keV}, \mathrm{I}_{\mathrm{ac}}=0.003 \mathrm{pA}$ ion beam. Each image (surface area of 500 $\mu \mathrm{m} \times 500 \mu \mathrm{m})$ was composed of $256 \times 256$ pixels. The total ion dose density of acquired 
images was $2.3 \times 10^{9} \mathrm{Bi}_{3}{ }^{++} \mathrm{cm}^{-2}$ in burst-sine 1 pulse mode. Positive ion mass spectra were calibrated using the $\mathrm{CH}_{3}{ }^{+}, \mathrm{C}_{2} \mathrm{H}_{3}{ }^{+}, \mathrm{C}_{3} \mathrm{H}_{5}{ }^{+}$and $\mathrm{C}_{4} \mathrm{H}_{7}{ }^{+}$peaks. Negative ion mass spectra were calibrated using the $\mathrm{CH}_{2}{ }^{-}, \mathrm{C}_{2} \mathrm{H}^{-}, \mathrm{C}_{3}^{-}$and $\mathrm{C}_{4} \mathrm{H}^{-}$peaks.

99 peaks were selected, from the positive spectra, including mainly signal from amino acids, salts, metal oxides and contaminations, and the sum of their intensities was defined as the total intensity $I_{\text {tot }}$. The relative intensity attributed to the signal from amino acids $\left(I_{\text {rel, } A A}\right)$ was obtained using the following equation:

$$
I_{\text {rel }, A A}=\frac{\sum I_{A A}}{I_{\text {tot }}-\sum I_{\text {salt }}}
$$

Where $I_{A A}$ is the intensity of peaks attributed to amino acids, and $I_{\text {salt }}$ is the intensity of peaks attributed to salts. $I_{r e l, A A}$ measured on reference native and OPA-conditioned samples was systematically subtracted from $I_{r e l, A A}$ of corresponding treated samples. All reported values are the average of three different positions on each sample.

\section{Sample preparation and characterization}

The process of Ti or SS surface modification using OPA self-assembly, then Plu and protein adsorption is shown schematically in Figure 1. Ti and SS were first coated by OPA as described above to obtain hydrophobic surfaces. Hydrophobized Ti and SS crystals were mounted in QCM cells, where Plu and protein adsorption were successively performed (sequential adsorption). In another set of experiments, hydrophobic Ti and SS coupons were incubated in a mixed Plu $\left(2 \mathrm{mg} \mathrm{mL}^{-1}\right)$ and protein (BSA at $\left.0.2 \mathrm{mg} \mathrm{mL}^{-1}\right)$ solution in artificial seawater for $2 \mathrm{~h}$ (competitive adsorption), then rinsed 10 times in ultrapure water, dried under a nitrogen flow and analyzed by ToF-SIMS and XPS. 


\section{Results \\ OPA coating on Ti and SS}

Ti/OPA and SS/OPA QCM crystals were characterized by WCA measurements, XPS and ToF-SIMS imaging. The WCA values are reported in Table 3 for Ti, and Table 4 for SS. The wettability of the native Ti and SS crystals was measured just after cleaning. While the WCA of native Ti and SS was $<10^{\circ}$, the hydrophobicity of metal oxide surfaces increased after OPA coating up to $105.5^{\circ} \pm 1.1^{\circ}$ and $99.3^{\circ} \pm 0.9^{\circ}$ for Ti and SS, respectively. The stability of OPA coating was also tested. After $90 \mathrm{~min}$ of ultrasonication in ultrapure water, the value of the WCA was still $100.0^{\circ} \pm 1.1^{\circ}$ and $100.9^{\circ} \pm 1.2^{\circ}$ for Ti/OPA and SS/OPA, respectively, showing the good stability of the coatings. After the same treatment, the value of WCA was still below $10^{\circ}$ for native Ti and SS.

The surface chemical composition obtained by XPS on Ti and SS crystals before and after OPA assembly is presented in Table 3 (Ti) and 4 (SS). Elements typical of these materials (Ti/O in a ratio close to 0.5 for $\mathrm{Ti} ; \mathrm{Fe}, \mathrm{Cr}, \mathrm{Mn}$ and $\mathrm{O}$ for $\mathrm{SS}$ ) were found as expected. A high level of carbon-based contamination was always observed (Kenausis et al. 2000) on native Ti and SS surface due to adventitious hydrocarbon from air or XPS chamber, and low concentrations of nitrogen, phosphorus, silicon and sulfur were detected as well. After OPA assembly, an increase in carbon and phosphorus content is observed as was expected from OPA composition. The ratio of $\mathrm{C} / \mathrm{P}$ was close to 18 , which is the expected value of $\mathrm{C} / \mathrm{P}$ in OPA molecules. Moreover, the atomic fraction of elements from the substrate ( $\mathrm{Ti}, \mathrm{Fe}, \mathrm{Cr}$ ) was significantly attenuated after OPA coating.

The C 1s spectra of Ti and SS before and after OPA coating are shown in Figure 2. The C 1s spectra of native Ti and SS (Figure 2a, 2c) are mainly composed of two peaks at $284.8 \mathrm{eV}$, due to carbon only bound to carbon and hydrogen $\underline{\mathrm{C}}-(\mathrm{C}, \mathrm{H})$, and at $286.2 \mathrm{eV}$, due to carbon bound to oxygen or nitrogen $\underline{\mathrm{C}}-(\mathrm{N}, \mathrm{O})$. These carbon species are considered as 
originating from organic contaminants present in the atmosphere, which are adsorbing on the native Ti and SS because of the high surface energy of these materials. After OPA coating, the $\mathrm{C} 1 \mathrm{~s}$ peaks were narrower (Figure $2 \mathrm{~b}, 2 \mathrm{~d}$ ). One single and symmetric peak component (Figure 2b) is found on Ti/OPA, with a binding energy of $284.8 \mathrm{eV}$, in agreement with the presence of $\underline{\mathrm{C}}-(\mathrm{C}, \mathrm{H})$ bonds from aliphatic chains in OPA. The $\underline{\mathrm{C}}-\mathrm{O}$ compound has disappeared, which indicates that contamination was removed and replaced by OPA molecules. The $\mathrm{C} 1 \mathrm{~s}$ spectrum of SS/OPA is similar to the one of Ti/OPA, except for a small residual component at about $286 \mathrm{eV}$. It might be attributed to defects of the OPA coating on SS, allowing the detection of some residual contamination.

ToF-SIMS spectra (data not shown) show high intensities of typical OPA molecular peaks on Ti/OPA and SS/OPA. ToF-SIMS imaging was used to check the homogeneity of OPA coating on Ti and SS. Images of total intensity from selected fragments typical of OPA $\left(\mathrm{C}_{2} \mathrm{H}_{4} \mathrm{PO}_{3}{ }^{-}, \mathrm{C}_{2} \mathrm{H}_{8} \mathrm{PO}_{3}^{-}, \mathrm{C}_{8} \mathrm{H}_{18} \mathrm{PO}_{3}^{-}, \mathrm{C}_{18} \mathrm{H}_{38} \mathrm{PO}_{2}^{-}, \mathrm{C}_{18} \mathrm{H}_{38} \mathrm{PO}_{3}^{-}\right)$recorded before and after OPA coating are presented in Figure 3. The images clearly highlight the presence of OPA at the surface after treatment (Figure 3b, 3d). On the contrary, only noise is detected on native Ti and SS (Figure 3a, 3c). The OPA coating also seemed more homogenous on Ti/OPA compared to SS/OPA.

\section{Monitoring Plu and protein sequential adsorption using QCM}

QCM has first been used to study Plu adsorption on SS, Ti, SS/OPA and Ti/OPA. Graphs showing the evolution of $\Delta \mathrm{f}$ and $\Delta \mathrm{D}$ with time are presented in Figure 4 . Both $\Delta \mathrm{f}$ and $\Delta \mathrm{D}$ are markedly larger on $\mathrm{Ti} / \mathrm{OPA}$ and $\mathrm{SS} / \mathrm{OPA}$ compared to $\mathrm{Ti}$ and $\mathrm{SS}$. On treated metal oxides, $\Delta \mathrm{f}$ decreased rapidly in the first $10 \mathrm{~min}$ and was associated to a clear $\Delta \mathrm{D}$ increase. After that, $\Delta \mathrm{f}$ still decreased slightly up to $\square 40 \mathrm{~Hz}$ in the next hour without any further dissipation shift. After rinsing with ASW to remove loosely adsorbed Plu, only a small 
increase of $\Delta \mathrm{f}$ was observed, associated with a more pronounced decrease of $\Delta \mathrm{D}$. The values of $\Delta \mathrm{f}$ and $\Delta \mathrm{D}$ at this stage reveal the adsorption of a significant amount of Plu on Ti/OPA and $\mathrm{SS} / \mathrm{OPA}$. In contrast, both $\Delta \mathrm{f}$ and $\Delta \mathrm{D}$ went back to baseline after rinsing on native $\mathrm{Ti}$ and $\mathrm{SS}$, which means that no significant amount of Plu remained adsorbed on these substrates.

The protein resistance ability of Plu on Ti and SS surfaces was examined in presence or absence of OPA coating. Figure 5 shows the results obtained by QCM. Protein adsorption was first monitored in absence of Plu adsorption step (solid lines). For a given type of surface, $\Delta \mathrm{f}$ was more negative and therefore the amount of adsorbed protein increased with increasing molecular mass of the protein $(\mathrm{CytC}<\mathrm{BSA}<\mathrm{Fb})$. For a given protein, the level of adsorption was however different on native and OPA-conditioned surfaces: BSA and CytC adsorption was favored on the native compared to the OPA-conditioned surfaces, while the contrary was observed for $\mathrm{Fb}$.

Plu preadsorption was carried out as follows: first, Plu was adsorbed for $2 \mathrm{~h}$ until saturation was reached. Then the surface was rinsed with artificial seawater to get a flat baseline again. For the sake of clarity, the baseline was set to zero at that stage. After that, protein adsorption was performed (see dashed lines in Figure 5). The changes of $\Delta \mathrm{f}$ were negligible after protein adsorption when Plu was preadsorbed on Ti/OPA and SS/OPA (Figure 5. dashed lines). This demonstrates the protein resistance of Plu coatings on Ti/OPA and SS/OPA. The control experiments presented in Figure 6 (dashed lines) prove that preadsorption of Plu on native Ti and SS does not allow protein adsorption to be prevented. The observed adsorption is indeed very similar to the one observed in the absence of Plu precoating on Ti or SS (Figure 6, solid lines).

\section{Competitive Plu and protein adsorption examined by XPS and ToF-SIMS}

Competitive adsorption from a mixed Plu and BSA solution was carried for $2 \mathrm{~h}$ on native and OPA-conditioned Ti and SS. Single adsorption experiments (BSA or Plu alone) 
were performed as control. It is clearly showed by previous QCM results (Figures 4 for Plu and $5 \mathrm{a}, 5 \mathrm{~b}$ for BSA) that $2 \mathrm{~h}$ is sufficient to reach the plateau of Plu and BSA adsorption. The extent of BSA adsorption on Ti or SS was examined by ToF-SIMS and XPS. The C 1s spectra obtained after BSA and/or Plu adsorption are shown in Figure 7. A small SiC component appeared at about $281.5 \mathrm{eV}$ on the native Ti surface, probably due to the polishing process. Except for that, very similar results were obtained for Ti and SS. Therefore, only the results for Ti will be described in the text.

The $\mathrm{C}$ 1s peaks recorded on Ti and Ti/OPA after BSA and/or Plu adsorption were decomposed in four components ( $\mathrm{SiC}$ was excluded): at $284.8 \mathrm{eV}$, due to carbon bound to carbon or hydrogen $\underline{\mathrm{C}}-(\mathrm{C}, \mathrm{H})$; at $286.2 \mathrm{eV}$, due to carbon bound to nitrogen or oxygen $\underline{\mathrm{C}}-(\mathrm{N}, \mathrm{O})$; at $288.0 \mathrm{eV}$, due to carbon from the peptidic link $(\mathrm{N}-\underline{\mathrm{C}}=\mathrm{O})$ which indicated the presence of protein; and at $289 \mathrm{eV}$, due to carbon from carboxylic acid or ester groups $(\mathrm{O}-\underline{\mathrm{C}}=\mathrm{O})$. The shape of $\mathrm{C} 1 \mathrm{~s}$ peaks recorded after BSA adsorption on native Ti surface in the absence and presence of Plu was similar (Figure 7(I)b, c), and the shape of the C 1s peaks recorded after single Plu adsorption was very close to the one obtained on native Ti (Figure 7(I)a, d). The

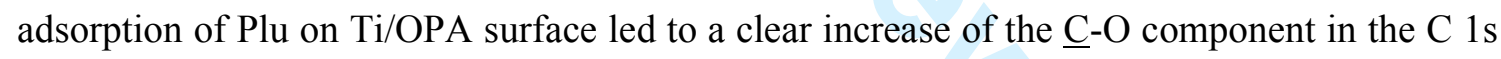
peak (Figure 7(II)a, d), in line with the composition of Plu. Finally, the C 1s peak obtained after competitive adsorption was very similar to the one obtained after single Plu adsorption (Figure 7(II)c, d). The XPS O 1s spectra (not shown) were less useful in this work because of the high intensity of oxygen coming from metal oxide surfaces.

After decomposition of the $\mathrm{N} 1 \mathrm{~s}$ peak (not shown here), amide (400.0 eV, $\underline{\mathrm{N}}-\mathrm{C}=\mathrm{O})$ molar fraction (in \%) was used as an indicator for the relative amount of BSA adsorbed on native Ti and Ti/OPA surface (Figure 8a). The amide content is close to zero when BSA is adsorbed together with Plu on Ti/OPA or SS/OPA, while it is similar to the one recorded in absence of Plu on Ti and SS. The intensities of fragments of amino acids from BSA measured 
on ToF-SIMS mass spectra $\left(I_{r e l, A A}\right)$ is plotted in Figure 8 together with the amide fraction measured by XPS, for the different experimental conditions. BSA is almost not detected after competitive adsorption with Plu on Ti/OPA and SS/OPA, while its signal is again similar to the one recorded in absence of Plu on Ti and SS.

\section{Discussion}

OPA assembly on Ti and SS was assessed by WCA, ToF-SIMS and XPS measurements. These complementary results indicate that a $\mathrm{CH}_{3}$-terminated hydrophobic layer was successfully formed on Ti/OPA and SS/OPA samples. Second, the protein resistance properties of Plu on Ti/OPA and SS/OPA were examined by sequential adsorption and competitive adsorption of $\mathrm{Plu}$ and model proteins. QCM results showed that the adsorption of these proteins (BSA, Fb and $\mathrm{CytC}$ ), taken as model fouling biomacromolecules, can be prevented on Ti/OPA and SS/OPA with preadsorption of Plu. The control experiments clearly showed a significant amount of protein adsorbed on both native and OPA-conditioned Ti and SS in absence of Plu. Adsorption of Plu on native Ti and SS surfaces did not prevent protein adsorption due to the lack of adsorption of Plu on these hydrophilic surfaces. Competitive adsorption of Plu and BSA on OPA-conditioned Ti and SS surfaces showed that BSA adsorption could be prevented or adsorbed BSA could be displaced on Ti/OPA and SS/OPA in the presence of Plu.

Self-assembly of small molecules, such as alkanethiols on gold (Love et al. 2005) and alkylsilanes on silica (Ulman 1996), produce well-ordered coatings which may be used to control wettability, biocompatibility and functional groups on the surface (Van Alsten 1999). Here, octadecylphosphonic acid (OPA) was self-assembled on Ti and SS surfaces because this strategy is well-suited for metal oxide surfaces. The thickness and structure of OPA layer was studied in detail elsewhere (Keszthelyi et al. 2006). Briefly, the mechanism of assembly is 
based on the reaction of phosphonic acid head group of OPA molecule with metal oxide on the surface, leaving alkyl chains pointing outwards, which interact through van der Waals forces. The presence of metal oxide at the extreme surface is necessary for the success of OPA self-assembly. This was the case here for Ti and SS (see elemental composition in Table 3 and 4, and shape of O 1s peaks, not shown here). The WCA measured after OPA assembly (see Table 3 and 4) are attributed to the terminal methyl groups of alkyl chains, pointing outward from the metal surface after treatment. Well-organized hydrophobic layers are thus obtained. XPS and ToF-SIMS results (see Figure 2 and 3) also point to the formation of a relatively homogeneous coating, and to the displacement of carbon-based contaminants upon assembly. The obtained OPA layer was somewhat less homogeneous on SS/OPA compared to Ti/OPA, maybe due to the fact that SS is an alloy.

It is clearly shown in Figure 5 that surface hydrophobicity influences protein adsorption. The adsorbed amount of BSA and CytC on Ti/OPA and SS/OPA was less than on native Ti and SS surfaces (Figure 5a, 5b, 5e, 5f). As calculated by Sauerbrey equation, the respective adsorbed mass of BSA and CytC are $\sim 630 \mathrm{ng} \mathrm{cm}^{-2}$ and $\sim 370 \mathrm{ng} \mathrm{cm}^{-2}$ on Ti, and $420 \mathrm{ng} \mathrm{cm}^{-2}$ and $130 \mathrm{ng} \mathrm{cm}^{-2}$ on Ti/OPA. Similar values are found on SS. Hydrophobic interaction is identified as the main driving force for BSA and CytC adsorption onto hydrophobic surfaces (van der Veen et al. 2007). It was shown (Roach et al. 2005) that BSA, a so-called soft protein, undergoes a structural rearrangement (deformation) when adsorbed on hydrophobic surfaces. Flattening of the protein molecules on the surface leads to a lower adsorbed amount because the area occupied per molecule increases and a monolayer is thus formed which contains fewer molecules. In contrast, fibrinogen is known to be a hard protein, with a rod shape (Nakanishi et al. 2001). Here, we show that it adsorbs more onto Ti/OPA and SS/OPA, compared to native Ti and SS (Figure 5c, 5d). The adsorbed mass of Fb was $\sim 950$ ng $\mathrm{cm}^{-2}$ on $\mathrm{Ti}$ and $\sim 1940 \mathrm{ng} \mathrm{cm} \mathrm{cm}^{-2}$ on Ti/OPA, respectively. This could be explained by 
orientation difference of $\mathrm{Fb}$ on these two different surfaces. On OPA-conditioned surfaces (Figure 5c, 5d), Fb adsorption may undergo a two-stage process, in which adsorbed fibrinogen may reorient to the "end-on" configuration, with the long axis of $\mathrm{Fb}$ perpendicular to the hydrophobic surface. A similar explanation was given by Roach et al (2005), and was attributed to attractive forces between fibrinogen molecules, which would be dominant on hydrophobic surfaces. On the native Ti and SS surfaces, most of Fb molecules may be in the "side-on" configuration, with the long axis parallel to the surface, which gives more contact area per $\mathrm{Fb}$ molecule. It is expected that electrostatic attraction force governs protein adsorption on native Ti and SS surfaces. Here, we observe that the adsorbed mass increases with the molecular mass of the proteins. This is not surprising since proteins tend to form monolayers, whose thickness increases with the size of the molecules. Such a trend may however not always be found, depending on the anisotropy of the molecules, their orientation once adsorbed, and their denaturation at the interface.

The PEO-PPO-PEO triblock copolymer adsorption mechanism is thought to be based on the hydrophobic interaction between PPO blocks and alkyl groups of OPA on Ti/OPA or SS/OPA surfaces. As shown in Figure 4, Plu adsorbs very fast $(\sim 10 \mathrm{~min})$ onto the OPAconditioned surfaces. This fast adsorption rate may be attributed to the abundant free sites for adsorption on hydrophobic surfaces in the beginning of the process. As more and more sites were occupied, the changes in frequency shift related to adsorption slowed down, and a plateau was reached. At this stage, it is assumed that Plu forms a brush structure with relatively high density on Ti/OPA and SS/OPA, which prevents further Plu molecules to approach (Nejadnik et al. 2009). It has been reported (Nejadnik et al. 2009) that PEO-PPOPEO can form a brush structure on hydrophobic surfaces with WCA above $80^{\circ}$, which is then effective to reduce protein adsorption (Schroen et al. 1995). In contrast, PEO-PPO-PEO can form a pancake structure on hydrophilic surfaces (Schroen et al. 1995), which is insufficient 
to prevent protein adsorption. However, QCM results obtained here indicate that Plu does not even remain in significant amount on the native Ti and SS after rinsing (Figure 4). This explains the similar results found for protein adsorption on Ti and SS in absence or presence of Plu adsorption step (see Figure 6). The extent of Pluronic adsorption on metallic surfaces might be related to their cleanness. It is known that, due to their high surface energy, metal substrates get contaminated by adsorption of adventitious hydrocarbon after exposure to ambient environment, resulting in increased WCA after cleaning. It is worth to point out here that the native Ti and SS crystals were used for QCM-D experiments just after the cleaning procedure, and were very hydrophilic $\left(\mathrm{WCA}<10^{\circ}\right)$.

The adsorbed Plu mass calculated based on Sauerbrey equation is equal to $460 \mathrm{ng} \mathrm{cm}^{-2}$ and $480 \mathrm{ng} \mathrm{cm}^{-2}$ on Ti/OPA and SS/OPA, respectively. Due to the similar values obtained on $\mathrm{Ti} / \mathrm{OPA}$ and SS/OPA, the average value of $470 \mathrm{ng} \mathrm{cm}^{-2}$ is used for further computation. It is assumed here that the hydrated Plu layer contained $20 \%$ to $50 \%$ of water based on previous literature results (Liu et al. 2010). Based on this range of water content, we estimated the number of adsorbed Plu molecules and PEO chains per unit area. The results give an estimated range of $0.17 \square 0.27 \mathrm{Plu}$ molecules $\mathrm{nm}^{-2}, 0.34 \square 0.54$ PEO chains $\mathrm{nm}^{-2}$ and $26 \square$ 41 EO monomers $\mathrm{nm}^{-2}$. The Plu density obtained here is in the same range as the one reported for Pluronic P105 ( $\left.\mathrm{PEO}_{37}-\mathrm{PPO}_{56}-\mathrm{PEO}_{37}\right)$ adsorption on hydrophobic polypropylene surface $\left(0.19 \square 0.21\right.$ molecules $\mathrm{nm}^{-2}$ ) (Liu et al. 2010). The PEO chain density or EO monomer density is a more critical value to evaluate the protein resistance ability of adsorbed Plu. It was indeed showed that the smaller proteins can penetrate and adsorb between PEO chains (Michel et al. 2005) if the PEO chain density is not high enough. The PEO density and EO monomer density obtained here are comparable with those achieved by adsorption of PLL(20)-g-PEG(2) $(\mathrm{g}<5)$ on $\mathrm{Nb}_{2} \mathrm{O}_{5}$ surface (Pasche et al. 2003), which showed a good protein resistance ability in serum solution. The PEO chain density could still be improved 
using Pluronic with different PPO and/or PEO chain lengths (Caldwell 1997).

The protein resistance ability of PEO-PPO-PEO triblock copolymer was tested by adsorption of proteins, and monitored by QCM. It was clearly shown (Figure 5) that protein adsorption was negligible on Ti/OPA and SS/OPA with preadsorbed Plu. These results show that the adsorption of all tested proteins (BSA, $\mathrm{Fb}$ and $\mathrm{CytC}$, with different molecular masses and shapes) can be prevented by pre-adsorption of Plu on Ti/OPA and SS/OPA, showing the versatility of the approach. Other studies also reported that adsorption of $\mathrm{Plu}$ on $\mathrm{CH}_{3}$ terminated self-assembled monolayer on gold prevents albumin and fibrinogen adsorption, as demonstrated by surface plasmon resonance (SPR) (Chang et al. 2010). The mechanism of protein resistance ability of PEO-PPO-PEO is attributed to the high hydration of PEO chains extending into the bulk solution, resulting in a steric barrier (Freij-Larsson et al. 1996; Green et al. 1998).

By comparing the QCM results for BSA (Figure 5a, 5b) and Plu (Figure 4a, 4b) adsorption on Ti/OPA and SS/OPA surfaces, it can be seen that BSA adsorption reaches saturation faster than Plu (in the conditions used here). Therefore, we may wonder if bringing Plu together with BSA in solution may still be relevant to prevent protein adsorption, or if it is necessary to pre-adsorb Plu to prevent BSA adsorption. Competitive adsorption was thus performed. The XPS (Figures 7 and 8) and ToF-SIMS (Figure 8) results show, in excellent agreement with each other, that prevention of protein adsorption is as well obtained when Plu is brought in solution together with the protein instead of being preadsorbed. This suggests that Plu might have a higher affinity toward hydrophobic surfaces compared to BSA and that adsorbed BSA could be replaced by Plu molecules. A similar result was reported by Dewez (1997). The presence of Pluronic F68 was shown to reduce collagen adsorption, and the effect was more pronounced as the substrate hydrophobicity was higher (Dewez et al. 1997). Other results of the same author showed that pre-adsorbed extracellular matrix (ECM) proteins are 
not displaced by Pluronic F68, whatever the substratum hydrophobicity (Dewez et al. 1999). The displacement kinetics of BSA or other fouling compounds by Plu might be related to the hydrophobicity of underlying substrate and the nature of these compounds. Furthermore, Detrait (1998) showed that Pluronic F68 reduces the adsorption of adhesive proteins (fibronectin or collagen) on hydrophobic polystyrene surface by competitive adsorption, thereby reducing cell adhesion (Detrait et al. 1998). The possibility to desorb an already formed conditioning film would open the way to an interesting strategy of decontamination of fouled surfaces. In undergoing work, we have actually shown that Pseudomonas adhesion on SS/OPA is strongly reduced by preadsorption of Plu, or by addition of Plu after the bacterial adhesion step (Yang et al, to be published).

\section{Conclusion}

The present work provides a two-step approach to create PEO-modified surfaces on metallic oxide surfaces (here, SS and Ti). First, the surfaces are modified by an OPA selfassembled coating which makes them hydrophobic. Then, a PEO-PPO-PEO copolymer (Plu) is adsorbed. Anchoring of the copolymer through its central PPO block is thought to occur, leaving free PEO chains in solution. The adsorption of three proteins (BSA, Fb and $\mathrm{CytC}$ ), used as model fouling biomolecules, was shown to be prevented on Ti and SS surfaces, previously hydrophobized and treated with Plu. The obtained PEO chain density on OPAconditioned Ti and SS is in the range of $0.3-0.5$ chains $\mathrm{nm}^{-2}$, which is comparable to the density measured on PLL-g-PEG adsorbed on metal oxide surfaces. A one-step approach was then investigated, in which the metal oxide surfaces are only modified by OPA self-assembly. Plu is then simply added to the fouling solution. The results show that in these conditions, prevention of protein adsorption is also successful. These approaches could be used to reduce bacterial adhesion and biofilm formation, and are applicable on other metal oxide surfaces as 
well. The adhesion properties of marine microorganisms on this anti-protein layer will be investigated further.

\section{Acknowledgements}

The authors thank Michel Genet for XPS results discussion and Dr. Kevin McEvoy for QCM training and discussion of protein adsorption results. The research leading to these results has received funding from the European Community's $7^{\text {th }}$ Framework Programme (FP7/2007-2013) under grant agreement No.238579. Funding by the Belgian National Foundation for Scientific Research (FNRS) and by BELSPO (Interuniversity Attraction Pole Program) is acknowledged as well. 


\section{References}

Amiji M, Park K. 1992. Prevention of protein adsorption and platelet adhesion on surfaces by PEO/PPO/PEO triblock copolymers. Biomaterials. 13:682-692.

Berglin M, Elwing H. 2008. Erosion of a model rosin-based marine antifouling paint binder as studied with quartz crystal microbalance with dissipation monitoring (QCM-D) and ellipsometry. Prog Org Coat. 61:83-88.

Boonaert CJP, Dufrêne YF, Rouxhet PG. 2003. Adhesion (Primary) of Microorganisms onto Surfaces. In: Encyclopedia of Environmental Microbiology. John Wiley \& Sons, Inc.

Caldwell KD. 1997. Surface Modifications with Adsorbed Poly(ethylene oxide)-Based Block Coploymers. In: Harris JM, Zalipsky S. Poly(ethylene glycol). American Chemical Society. p. 400-419.

Callow JA, Callow ME. 2011. Trends in the development of environmentally friendly fouling-resistant marine coatings. Nat Commun. 2:244.

Carter DC, Ho JX. 1994. Structure of Serum Albumin. Adv Protein Chem. 45:153-203.

Chang Y, Chu WL, Chen WY, Zheng J, Liu L, Ruaan RC, Higuchi A. 2010. A systematic SPR study of human plasma protein adsorption behavior on the controlled surface packing of self-assembled poly(ethylene oxide) triblock copolymer surfaces. J Biomed Mater Res A. 93:400-408.

Chen LJ, Chen M, Zhou HD, Chen JM. 2008. Preparation of super-hydrophobic surface on stainless steel. Appl Surf Sci. 255:3459-3462.

Chmielewski RAN, Frank JF. 2003. Biofilm Formation and Control in Food Processing Facilities. Compr Rev Food Sci F. 2:22-32.

Coetser SE, Cloete TE. 2005. Biofouling and biocorrosion in industrial water systems. Crit Rev Microbiol. 31:213-232.

Compère C, Bellon-Fontaine MN, Bertrand $\mathrm{P}$, Costa D, Marcus P, Poleunis C, Pradier CM, Rondot B, Walls MG. 2001. Kinetics of conditioning layer formation on stainless steel immersed in seawater. Biofouling. 17:129-145.

Cristiani P. 2005. Solutions to fouling in power station condensers. Appl Therm Eng. 25:2630-2640.

Dekeyser CM, Buron CC, Derclaye SR, Jonas AM, Marchand-Brynaert J, Rouxhet PG. 2012. Degradation of bare and silanized silicon wafer surfaces by constituents of biological fluids. J Colloid Interface Sci. 378:77-82.

Dekeyser CM, Buron CC, Mc Evoy K, Dupont-Gillain CC, Marchand-Brynaert J, Jonas AM, Rouxhet PG. 2008. Oligo(ethylene glycol) monolayers by silanization of silicon wafers: Real nature and stability. J Colloid Interface Sci. 324:118-126.

Detrait E, Lhoest JB, Knoops B, Bertrand P, van den Bosch de Aguilar P. 1998. Orientation of cell adhesion and growth on patterned heterogeneous polystyrene surface. J Neurosci Methods. 84:193-204.

Dewez J-L, Doren A, Schneider Y-J, Rouxhet PG. 1999. Competitive adsorption of proteins: Key of the relationship between substratum surface properties and adhesion of epithelial cells. Biomaterials. 20:547-559.

Dewez JL, Schneider YJ, Rouxhet PG. 1996. Coupled influence of substratum hydrophilicity and surfactant on epithelial cell adhesion. J Biomed Mater Res. 30:373-383.

Dewez JL, Berger VV, Schneider YJ, Rouxhet PG. 1997. Influence of Substrate Hydrophobicity on the Adsorption of Collagen in the Presence of Pluronic F68, Albumin, or Calf Serum. J Colloid Interface Sci. 191:1-10.

Fonder G, Minet I, Volcke C, Devillers S, Delhalle J, Mekhalif Z. 2011. Anchoring of alkylphosphonic derivatives molecules on copper oxide surfaces. Appl Surf Sci. 257:6300-6307. 
Freij-Larsson C, Nylander T, Jannasch P, Wesslen B. 1996. Adsorption behaviour of amphiphilic polymers at hydrophobic surfaces: effects on protein adsorption. Biomaterials. 17:2199-2207.

Gawalt ES, Avaltroni MJ, Koch N, Schwartz J. 2001. Self-Assembly and Bonding of Alkanephosphonic Acids on the Native Oxide Surface of Titanium. Langmuir. 17:5736-5738.

Green RJ, Davies MC, Roberts CJ, Tendler SJ. 1998. A surface plasmon resonance study of albumin adsorption to PEO-PPO-PEO triblock copolymers. J Biomed Mater Res. 42:165-171.

Green RJ, Tasker S, Davies J, Davies MC, Roberts CJ, Tendler SJB. 1997. Adsorption of PEO-PPO-PEO Triblock Copolymers at the Solid/Liquid Interface: A Surface Plasmon Resonance Study. Langmuir. 13:6510-6515.

Haynes CA, Norde W. 1994. Globular proteins at solid/liquid interfaces. Colloids Surf B Biointerfaces. 2:517-566.

Helmy R, Fadeev AY. 2002. Self-Assembled Monolayers Supported on TiO2: Comparison of $\mathrm{C} 18 \mathrm{H} 37 \mathrm{SiX} 3(\mathrm{X}=\mathrm{H}, \mathrm{Cl}, \mathrm{OCH} 3), \mathrm{C} 18 \mathrm{H} 37 \mathrm{Si}(\mathrm{CH} 3) 2 \mathrm{Cl}$, and $\mathrm{C} 18 \mathrm{H} 37 \mathrm{PO}(\mathrm{OH}) 2$. Langmuir. 18:8924-8928.

Hoque E, DeRose JA, Bhushan B, Hipps KW. 2009. Low adhesion, non-wetting phosphonate self-assembled monolayer films formed on copper oxide surfaces. Ultramicroscopy. 109:1015-1022.

Kenausis GL, Vörös J, Elbert DL, Huang N, Hofer R, Ruiz-Taylor L, Textor M, Hubbell JA, Spencer ND. 2000. Poly(l-lysine)-g-Poly(ethylene glycol) Layers on Metal Oxide Surfaces: Attachment Mechanism and Effects of Polymer Architecture on Resistance to Protein Adsorption†े. J Phys Chem B. 104:3298-3309.

Keszthelyi T, Paszti Z, Rigo T, Hakkel O, Telegdi J, Guczi L. 2006. Investigation of solid surfaces modified by Langmuir-Blodgett monolayers using sum-frequency vibrational spectroscopy and X-ray photoelectron spectroscopy. J Phys Chem B. 110:8701-8714.

Kingshott P, Griesser HJ. 1999. Surfaces that resist bioadhesion. Curr Opin Solid State Mater Sci. 4:403-412.

Kruszewski KM, Renk ER, Gawalt ES. 2012. Self-assembly of organic acid molecules on the metal oxide surface of a cupronickel alloy. Thin Solid Films. 520:4326-4331.

Leckband D, Sheth S, Halperin A. 1999. Grafted poly(ethylene oxide) brushes as nonfouling surface coatings. Journal of biomaterials science Polymer edition. 10:1125-1147.

Li L, Breedveld V, Hess DW. 2012. Creation of superhydrophobic stainless steel surfaces by acid treatments and hydrophobic film deposition. ACS Appl Mater Interfaces. 4:45494556.

Liu X, Wu D, Turgman-Cohen S, Genzer J, Theyson TW, Rojas OJ. 2010. Adsorption of a nonionic symmetric triblock copolymer on surfaces with different hydrophobicity. Langmuir. 26:9565-9574.

Love JC, Estroff LA, Kriebel JK, Nuzzo RG, Whitesides GM. 2005. Self-assembled monolayers of thiolates on metals as a form of nanotechnology. Chem Rev. 105:11031169.

Marx KA. 2003. Quartz crystal microbalance: a useful tool for studying thin polymer films and complex biomolecular systems at the solution-surface interface. Biomacromolecules. 4:1099-1120.

Michel R, Pasche S, Textor M, Castner DG. 2005. Influence of PEG architecture on protein adsorption and conformation. Langmuir. 21:12327-12332.

Nakanishi K, Sakiyama T, Imamura K. 2001. On the adsorption of proteins on solid surfaces, a common but very complicated phenomenon. J Biosci Bioeng. 91:233-244. 
Nejadnik MR, van der Mei HC, Norde W, Busscher HJ. 2008. Bacterial adhesion and growth on a polymer brush-coating. Biomaterials. 29:4117-4121.

Nejadnik MR, Olsson AL, Sharma PK, van der Mei HC, Norde W, Busscher HJ. 2009. Adsorption of pluronic F-127 on surfaces with different hydrophobicities probed by quartz crystal microbalance with dissipation. Langmuir. 25:6245-6249.

Nie HY. 2010. Revealing different bonding modes of self-assembled octadecylphosphonic acid monolayers on oxides by time-of-flight secondary ion mass spectrometry: silicon vs aluminum. Anal Chem. 82:3371-3376.

Page K, Wilson M, Parkin IP. 2009. Antimicrobial surfaces and their potential in reducing the role of the inanimate environment in the incidence of hospital-acquired infections. $\mathrm{J}$ Mater Chem. 19:3819-3831.

Pasche S, De Paul SM, Vörös J, Spencer ND, Textor M. 2003. Poly(l-lysine)-graftpoly(ethylene glycol) Assembled Monolayers on Niobium Oxide Surfaces: A Quantitative Study of the Influence of Polymer Interfacial Architecture on Resistance to Protein Adsorption by ToF-SIMS and in Situ OWLS. Langmuir. 19:9216-9225.

Reviakine I, Johannsmann D, Richter RP. 2011. Hearing what you cannot see and visualizing what you hear: interpreting quartz crystal microbalance data from solvated interfaces. Anal Chem. 83:8838-8848.

Roach P, Farrar D, Perry CC. 2005. Interpretation of protein adsorption: surface-induced conformational changes. J Am Chem Soc. 127:8168-8173.

Rosenhahn A, Schilp S, Kreuzer HJ, Grunze M. 2010. The role of "inert" surface chemistry in marine biofouling prevention. Phys Chem Chem Phys. 12:4275-4286.

Schneider RP, Leis A. 2003. Conditioning Films in Aquatic Environments. In: Encyclopedia of Environmental Microbiology. John Wiley \& Sons, Inc.

Schroen CGPH, Stuart MAC, van der Voort Maarschalk K, van der Padt A, van't Riet K. 1995. Influence of Preadsorbed Block Copolymers on Protein Adsorption: Surface Properties, Layer Thickness, and Surface Coverage. Langmuir. 11:3068-3074.

Ulman A. 1996. Formation and Structure of Self-Assembled Monolayers. Chem Rev. 96:1533-1554.

Van Alsten JG. 1999. Self-Assembled Monolayers on Engineering Metals: Structure, Derivatization, and Utility. Langmuir. 15:7605-7614.

van der Veen M, Stuart MC, Norde W. 2007. Spreading of proteins and its effect on adsorption and desorption kinetics. Colloids Surf B Biointerfaces. 54:136-142.

Yang Y, Rouxhet PG, Chudziak D, Telegdi J, Dupont-Gillain CC. Influence of poly(ethylene oxide) on protein adsorption and bacterial adhesion on stainless steel: modulation by surface hydrophobicity. To be published.

Zhao B, Brittain WJ. 2000. Polymer brushes: surface-immobilized macromolecules. Prog Polym Sci. 25:677-710. 
Table 1. Examples of fouling issues in various industries, and involved metals. ( $\mathrm{SS}=$ stainless steel).

\begin{tabular}{llll}
\hline Fouling issue & Industry & Metal involved & References \\
\hline Biocorrosion in pipelines & Oil industry & Carbon steel & Coetser and Cloete (2005) \\
Reduced efficiency of heat exchange & Power plant & Ti, SS, copper alloys & Cristiani (2005) \\
Food spoilage & Food process & SS & Chmielewski and Frank (2003) \\
Implant infection & Biomaterials & Ti and its alloys & Page et al. (2009) \\
Increased frictional drag and fuel consumption & Marine vessels & Steel & Callow and Callow (2011) \\
\hline
\end{tabular}


Table 2. Composition of artificial seawater used in this work.

\begin{tabular}{lcc}
\hline & $\mathrm{mmol} \mathrm{L}^{-1}$ & $\mathrm{~g} \mathrm{~L}^{-1}$ \\
\hline $\mathrm{NaCl}$ & 421.2 & 24.62 \\
$\mathrm{KCl}$ & 10.5 & 0.78 \\
$\mathrm{Na}_{2} \mathrm{SO}_{4}$ & 28.9 & 4.11 \\
$\mathrm{MgCl}_{2} \cdot\left(\mathrm{H}_{2} \mathrm{O}\right)_{6}$ & 54.4 & 11.06 \\
$\mathrm{CaCl}_{2} \cdot\left(\mathrm{H}_{2} \mathrm{O}\right)_{2}$ & 10.6 & 1.56 \\
\hline
\end{tabular}

1

2

3

4

5

6

10

10

11

13

14

15

16

17

18

19

20

21

22

23

24

25

26

27

28

29

30

31

32

33

34

35

36

37

38

39

40

41

42

43

44

45

46

47

48

49

50

51

52

53

54

55

56

57

58

59

60 
1

2

3

4

5

6

7

8

9

10

11

12

13

14

15

16

17

18

19

20

21

22

23

24

25

26

27

28

29

30

31

32

33

34

35

36

37

38

39

40

41

42

43

44

45

46

47

48

49

50

51

52

53

54

55

56

57

58

59

60

Table 3. Elemental surface composition (at. \%) and C/P elemental ratio determined by XPS, and water contact angle $\left(\theta_{\mathrm{w}}\right)$ value for Ti before and after OPA self-assembly, bdl = below detection limit $(<0.1 \%)$.

\begin{tabular}{lcccccccc}
\hline & $\mathrm{O}$ & $\mathrm{Ti}$ & $\mathrm{N}$ & $\mathrm{C}$ & $\mathrm{P}$ & $\mathrm{Si}$ & $\mathrm{C} / \mathrm{P}$ & $\theta_{\mathrm{w}}\left(^{\circ}\right)$ \\
\hline $\mathrm{Ti}$ & 47.3 & 21.0 & 0.9 & 29.9 & 0.7 & 0.2 & 42.7 & $<10$ \\
$\mathrm{Ti} / \mathrm{OPA}$ & 33.0 & 15.9 & 1.0 & 48.0 & 2.1 & bdl & 22.9 & $105.5 \pm 1.1$ \\
\hline
\end{tabular}


Table 4. Elemental surface composition (at. \%) and C/P elemental ratio determined by XPS, and water contact angle $\left(\theta_{\mathrm{w}}\right)$ value for SS before and after OPA self-assembly.

\begin{tabular}{lccccccccccc}
\hline & $\mathrm{Fe}$ & $\mathrm{Mn}$ & $\mathrm{Cr}$ & $\mathrm{O}$ & $\mathrm{N}$ & $\mathrm{C}$ & $\mathrm{S}$ & $\mathrm{P}$ & $\mathrm{Si}$ & $\mathrm{C} / \mathrm{P}$ & $\theta_{\mathrm{w}}\left({ }^{\circ}\right)$ \\
\hline $\mathrm{SS}$ & 13.2 & 0.1 & 3.7 & 44.7 & 0.5 & 34.1 & 0.2 & 1.1 & 2.4 & 31.0 & $<10$ \\
$\mathrm{SS} / \mathrm{OPA}$ & 8.6 & 0.1 & 2.3 & 34.2 & 0.8 & 48.4 & 0.5 & 2.6 & 2.4 & 18.6 & $99.3 \pm 0.9$ \\
\hline
\end{tabular}




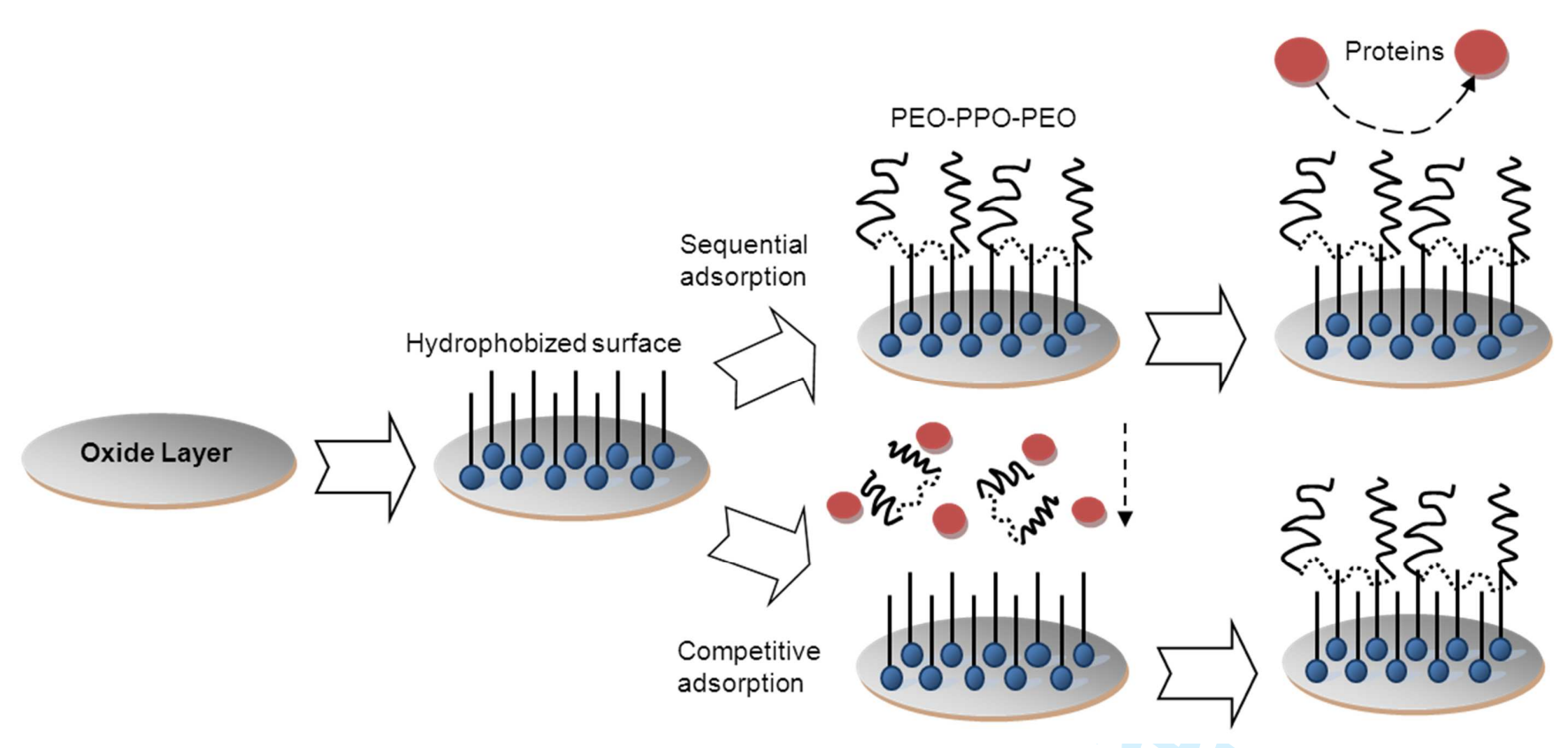

Figure 1. Surface modification strategy used in this work, and expected outcome. 

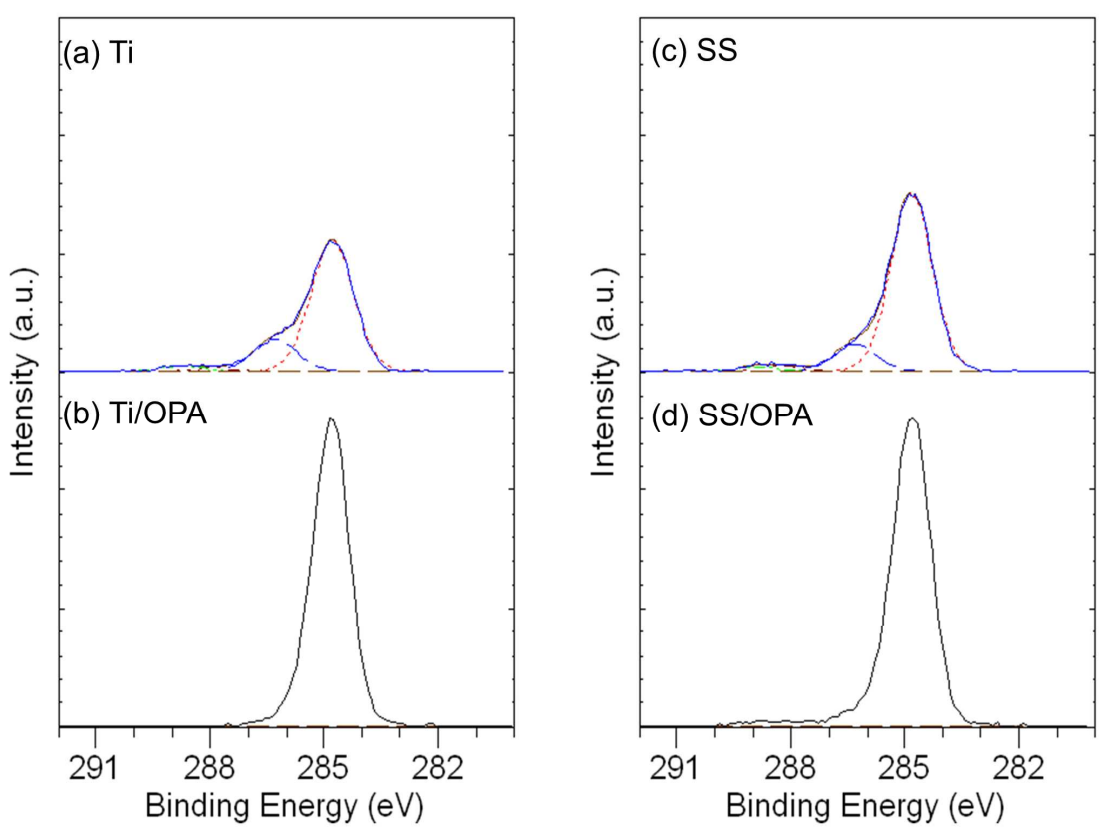

Figure 2. C 1s XPS spectra of (a) Ti, (b) Ti/OPA, (c) SS, (d) SS/OPA. 

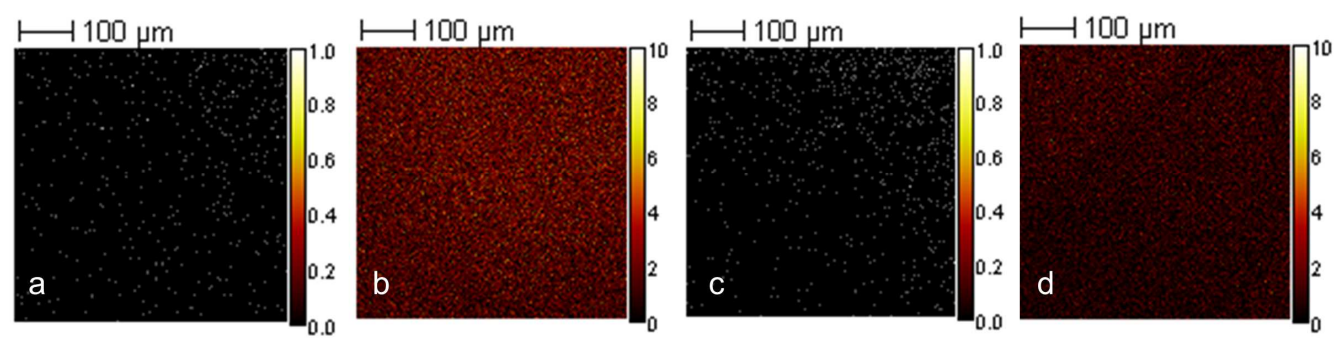

Figure 3. Field of view of $500 \mu \mathrm{m} \times 500 \mu \mathrm{m}$ negative ToF-SIMS images, showing the sum of $\mathrm{C}_{2} \mathrm{H}_{4} \mathrm{PO}_{3}^{-}, \mathrm{C}_{2} \mathrm{H}_{8} \mathrm{PO}_{3}^{-}, \mathrm{C}_{8} \mathrm{H}_{16} \mathrm{PO}_{3}^{-}, \mathrm{C}_{18} \mathrm{H}_{38} \mathrm{PO}_{2}^{-}, \mathrm{C}_{18} \mathrm{H}_{38} \mathrm{PO}_{3}^{-}$peak intensities on (a) clean Ti, (b) Ti/OPA, (c) clean SS, (d) SS/OPA. 

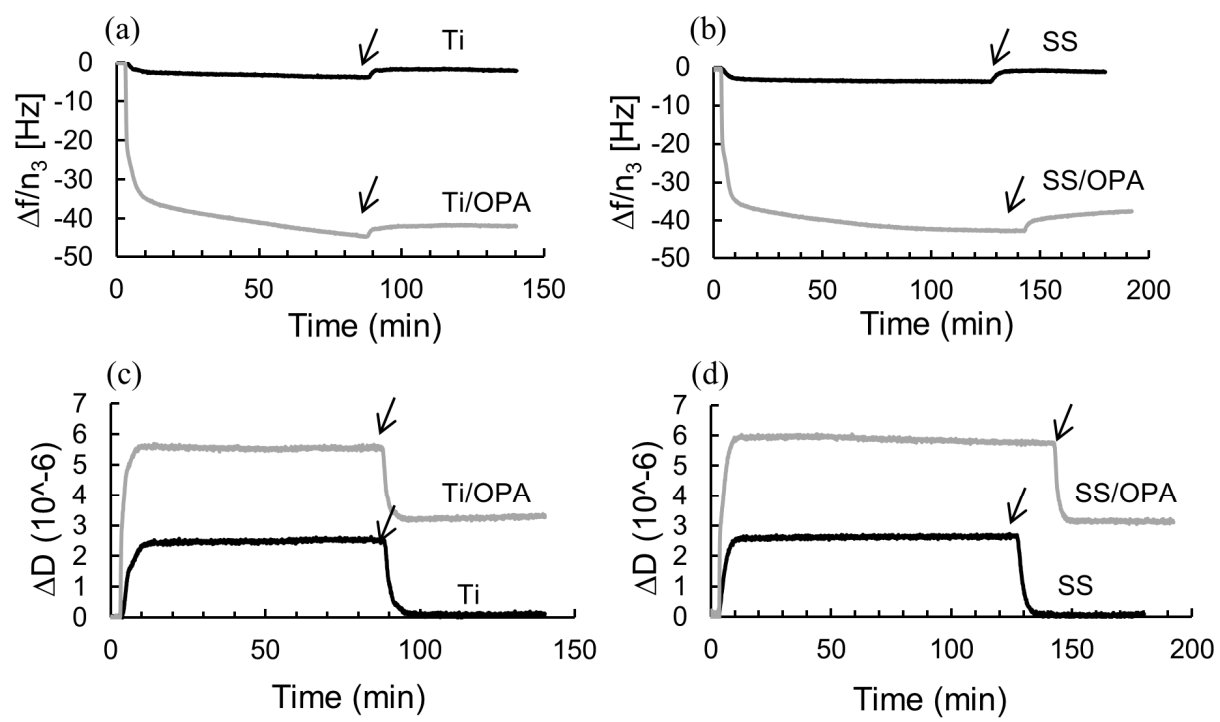

Figure 4. $\Delta \mathrm{f}$ vs time $(\mathrm{a}, \mathrm{b})$ and $\Delta \mathrm{D}$ vs time $(\mathrm{c}, \mathrm{d})$ for Plu $\left(2 \mathrm{mg} \mathrm{ml}^{-1}\right)$ adsorption on $(\mathrm{a}, \mathrm{c})$ Ti or Ti/OPA; (b, d) SS or SS/OPA. Arrows indicate rinsing using ASW. The results shown here were recorded from the $3^{\text {rd }}$ overtone. 
BSA

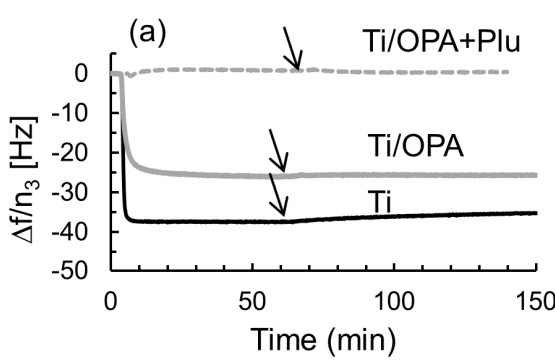

$\mathrm{Fb}$
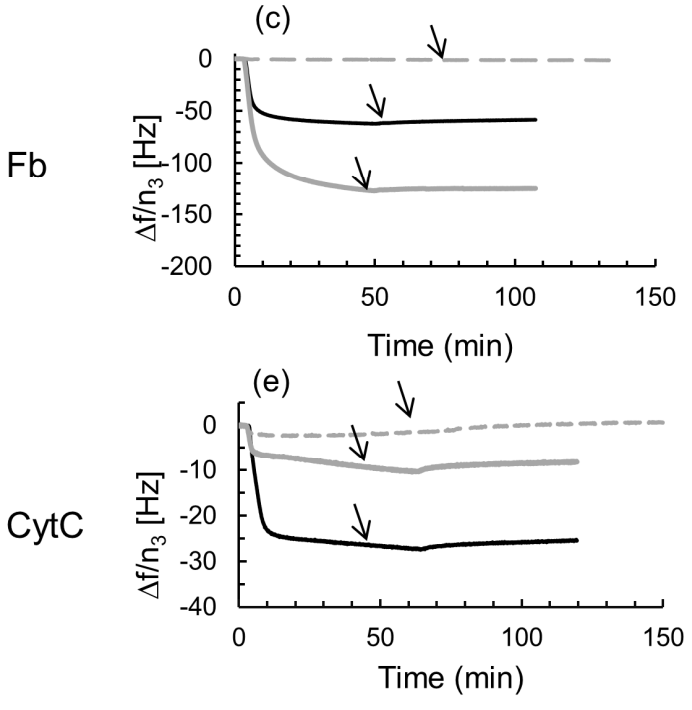
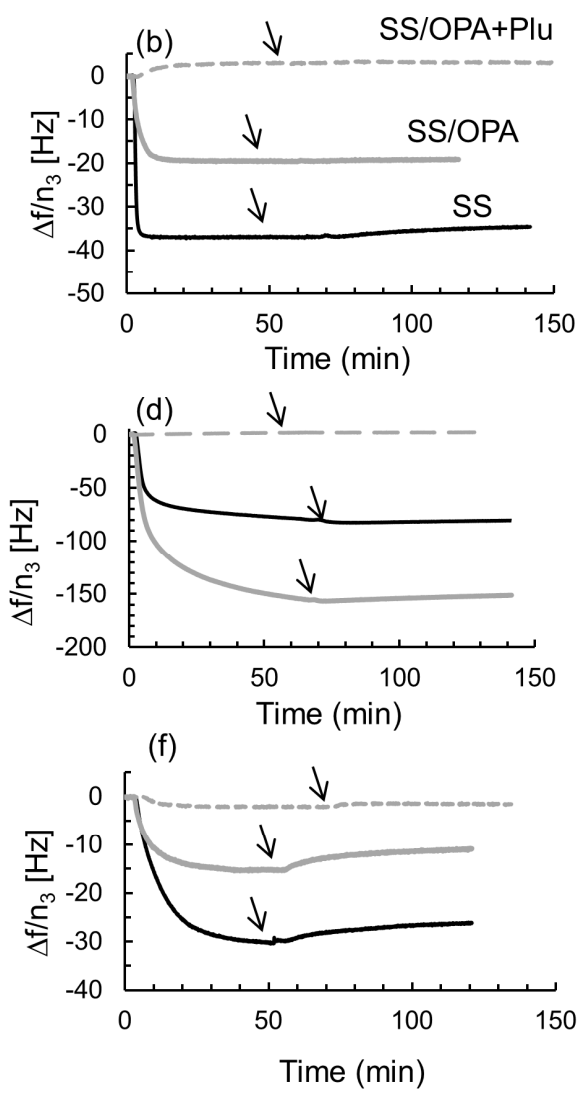

Figure 5. $\Delta \mathrm{f}$ vs time for the adsorption of different proteins (a, b: BSA), (c, d: Fb), (e, f: $\mathrm{CytC}$ ) on $\mathrm{Ti}(\mathrm{a}, \mathrm{c}, \mathrm{e})$ and $\mathrm{SS}(\mathrm{b}, \mathrm{d}, \mathrm{f})$ with different surface conditions (black: native; grey: +OPA; dashed line: +OPA+Plu). OPA coating was prepared before QCM experiment, and Plu adsorption was performed within the same QCM experiment. All graphs were however set to $\Delta \mathrm{f}=0$ at $\mathrm{t}=0 \mathrm{~min}$ when protein adsorption started, to allow comparisons to be made. Arrows indicate ASW rinsing after protein adsorption. 

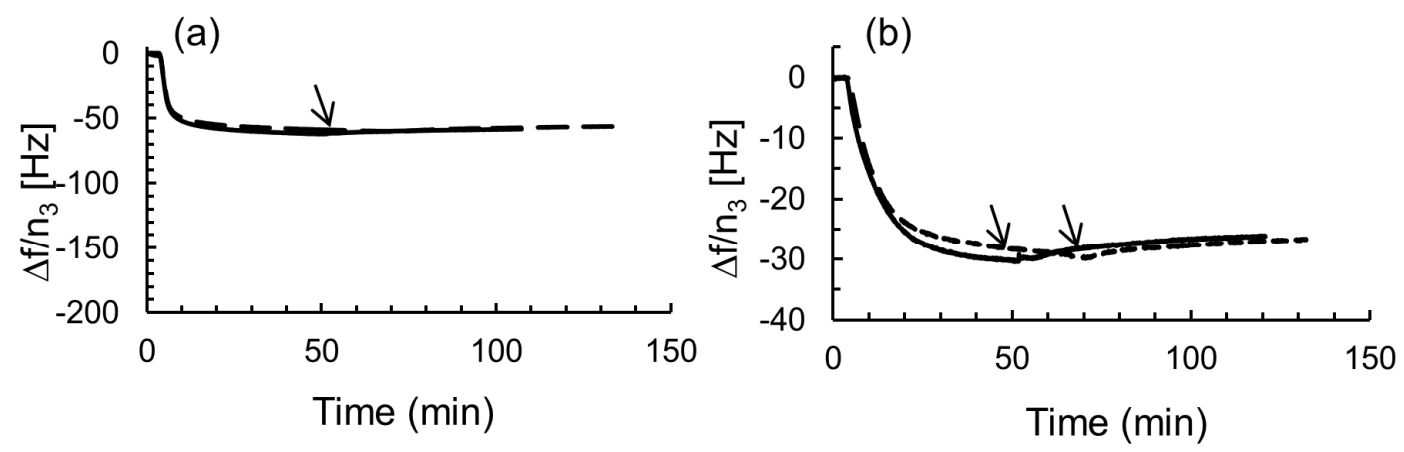

Figure 6. $\Delta \mathrm{f}$ vs time for the adsorption of $\mathrm{Fb}$ on $\mathrm{Ti}(\mathrm{a})$ and of CytC on $\mathrm{SS}(\mathrm{b})$ with (dashed line) or without (solid line) preadsorption of Plu. Plu adsorption was performed within the same QCM experiment. All graphs were however set to $\Delta \mathrm{f}=0$ at $\mathrm{t}=0 \mathrm{~min}$ when protein adsorption started, to allow comparisons to be made. Arrows indicate ASW rinsing after protein adsorption. 
(I) $\mathrm{T}$

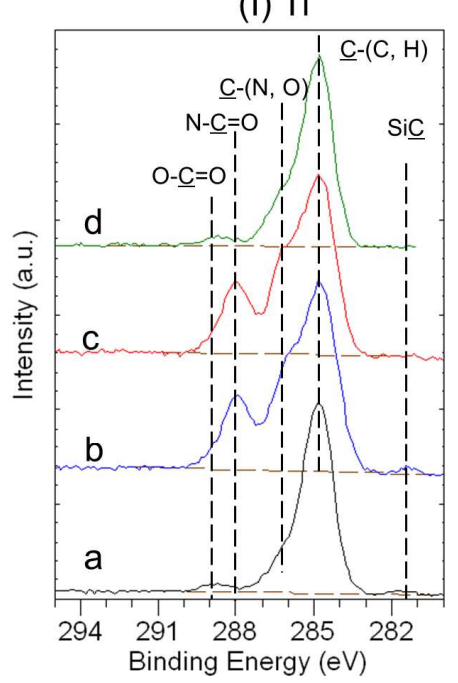

(III) SS

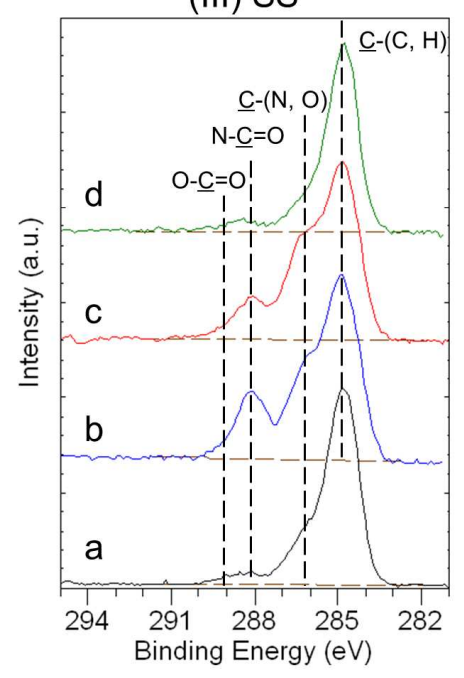

(II) Ti/OPA

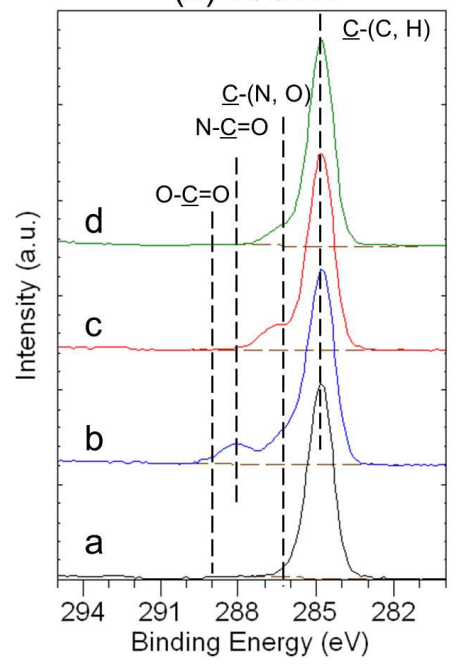

(IV) SS/OPA

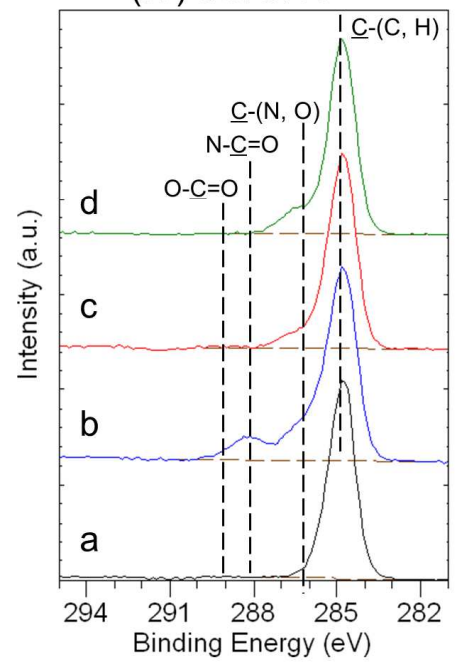

Figure 7. C 1s spectra of Ti (I), Ti/OPA (II), SS (III), SS/OPA (IV) conditioned with: (a)ASW, (b)single BSA adsorption, (c)BSA adsorption in the presence of Plu, (d)single Plu adsorption. The $\mathrm{C} 1 \mathrm{~s}$ peaks were normalized in such a way that their maxima have the same height. Peak intensities can thus not be directly compared here. Attribution of the components of the $\mathrm{C} 1 \mathrm{~s}$ peak is reported. 

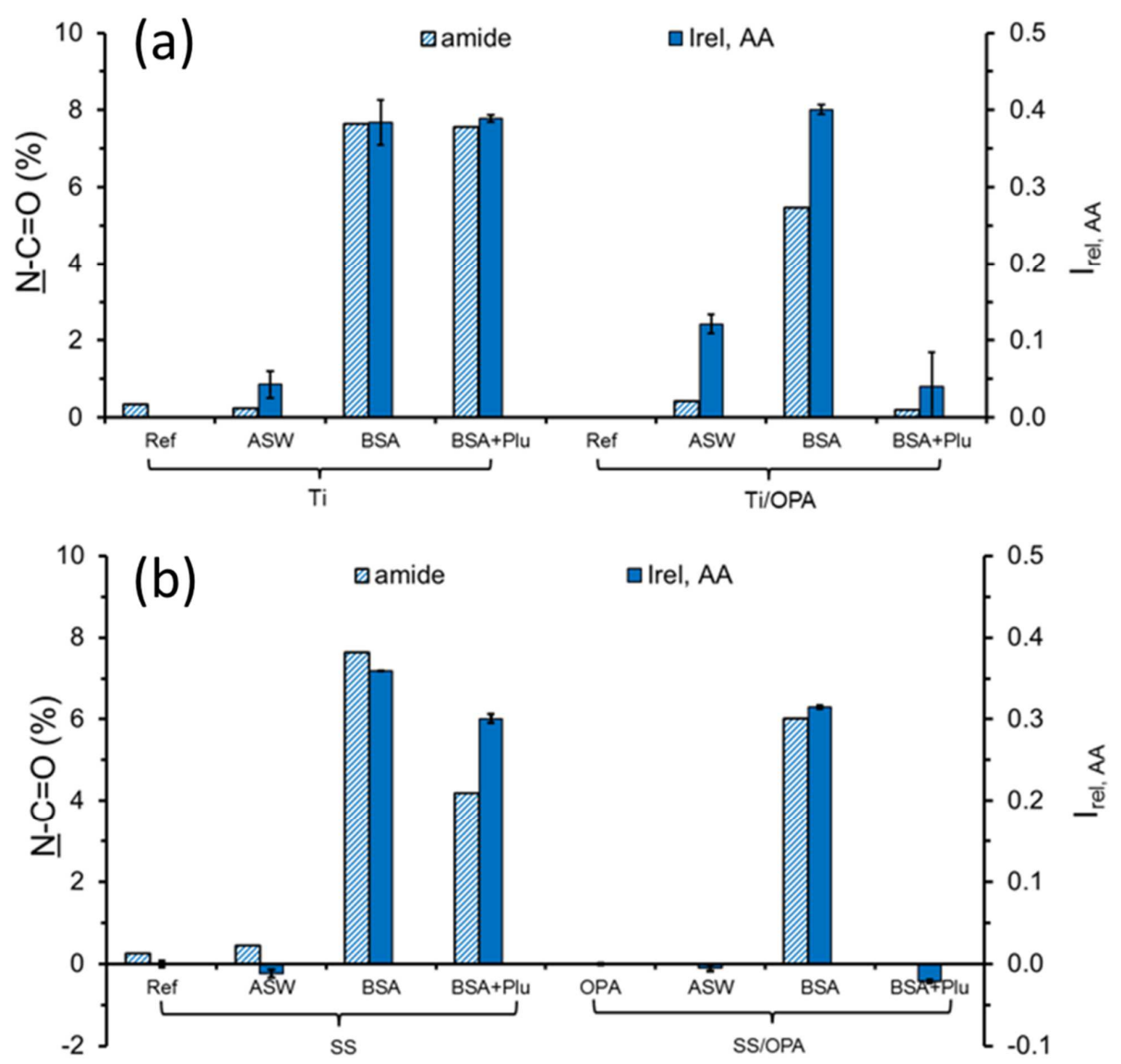

Figure 8. Amide $(\underline{N}-\mathrm{C}=\mathrm{O})$ mole fraction (in \%) determined by XPS and relative amino acid intensities ( $\mathrm{I}_{\text {rel, AA }}$ ) measured by ToF-SIMS on Ti (a) and SS (b) with or without OPA coating for BSA adsorption in the presence or absence of Plu. $I_{r e l, A A}$ measured on reference native and OPA-conditioned samples was systematically subtracted from $I_{r e l}$, $A A$ of corresponding treated samples. 